\title{
Shaanxi Cultural External Communication Strategy and Teaching Reflection under the Background of the Belt and Road
}

\author{
Xiong Guofang \\ School of Foreign Studies,Xi'an University,710065
}

Keywords: The Belt and Road; Shaanxi Culture; Strategy

\begin{abstract}
The proposal of the Belt and Road has provided an important opportunity for traditional culture to go to the world. As the starting point of the ancient Silk Road, Shaanxi should fully examine its unique advantages in culture and strengthen its cultural outbound strategy. To promote Shaanxi culture and implement the strategy of going abroad under the background of the Belt and Road is not only a social issue but also an education issue.
\end{abstract}

\section{Introduction}

Shaanxi Province is located in the northwest of China and it belongs to the middle undeveloped area in terms of comprehensive strength. However, from a cultural perspective, Shaanxi is a major and strong cultural province. Shaanxi Province has a long history and famous national culture. Shaanxi is one of the important birthplaces of splendid ancient civilizations in China. It is the most important and concentrated birthplace of Chinese civilization. About 800,000 years ago, Lantian monks had already lived in this land. The Banpo site in Xi'an shows the progress and civilization of the matrilineal clan community 6,000 years ago. From the Western Zhou Dynasty, the development of Shaanxi entered a new period. Zhou was an ancient tribe in Guanzhong, Shaanxi Province and their main activity center in Zhouyuan. The Gregorian calendar in Zhou Dynasty was the earliest calendar in China. All the buildings from one side prove the profoundness of Shaanxi culture, such as Qin E Fanggong, Qin Shi Huang Mausoleum, Hanyang Mausoleum, Qian Mausoleum, Xi'an City Wall, Bell Drum Tower and others. The friends at home and abroad who have visited Shaanxi tourism are often deeply attracted by Shaanxi's huge cultural charm.

In terms of opening up to the outside world, Shaanxi is also one of the regions where China opened up earlier. Ancient Chang'an has already had close economic and trade contacts with many countries and regions. The famous Silk Road is based on ancient Chang'an.

At present, the Belt and Road strategy has been widely recognized and widely promoted by relevant countries. How to take the opportunity of the Belt and Road to allow Shaanxi culture to go abroad and put new vitality into Shaanxi's culture has become a focus both in culture and education.

\section{The Cultural Going out Strategy under the Background of Belt and Road}

The Belt and Road is a major strategic move that China has taken in order to promote foreign trade and cultural exchanges, promote regional cooperation and strengthen international relations during the new historical period. It is possible to link countries along the Asia and Europe together through this initiative. This not only contains a huge space for commercial trade, but also provides ample channels for cultural exchanges between countries along the route. China's economic, trade, and cultural exchanges with the countries along the Belt and Road have never stopped and have maintained a good tradition. However, this kind of communication has never progressed from a deeper and broader aspect like today. The implementation of the Belt and Road strategy has greatly promoted the cultural exchanges between countries.

Since the reform and opening up, as China's ties with other countries in the world have become increasingly closer, the outward movement of Chinese culture has gradually developed into a realistic and urgent need. However, objectively speaking, our country's cultural outbound strategy is still relatively backward and it is basically in a weak and low-end development stage. The development of cultural output capacity and overall national stren gth cannot yet completely match. 
Shaanxi Province is even more so in this respect than the coastal developed provinces. Although it has a profound cultural background, the realization of Shaanxi's cultural strategy to go global still has a long way to go.

\section{Current Situation of Shaanxi Cultural Industry}

In order to actively cooperate with the Belt and Road Initiative and the needs of its own development, Shaanxi Province has made daring attempts and continuous innovation in the adjustment and promotion of the cultural industry in recent years. Under the guidance and encouragement of relevant policy and fully relying on the region's resource advantages, Shaanxi Province will try to enlarge and strengthen the cultural industry in an all-round way and form an industry development mode with Shaanxi characteristics based on resource and government. However, there are still some problems in the development of cultural industries in Shaanxi, such as the backwardness of concepts, the incomplete system and mechanism, the shortage of funds, and the relatively scarcity of talents, which seriously plague the sustainable development of Shaanxi's cultural industry.

The Concept Is Relatively Backward and Lack of Understanding of the Importance of Cultural Industries. Although Shaanxi people guard a huge cultural treasure, they tend to be conservative and backward in terms of their ideas. As the birthplace of Chinese farming culture, Shaanxi people have a strong cultural quality and personality that does not meet the industrial and commercial society and market economy. At present, many Shaanxi people are not only ideologically not objectively aware of the culture going out, but also maintain vigilance and resistance to the spread of foreign culture. In terms of strategic layout, Shaanxi cultural industry has not completely escaped the shackles of the planned economic system. The planned economic system has become the structural obstacle to the advancement of Shaanxi's cultural industry. This mode is not conducive to the cultural industry going to the market and not conducive to stimulating the social forces to invest in the construction of the cultural industry. At the same time, it has also increased the burden on the government to some extent. The decentralized power of cultural industry, single form and weak non-public ownership force have made the development of the Shaanxi cultural industry slow.

Insufficient Overall Investment and Limited Channels. The lack of comprehensive social strength and government investment is an important factor restricting the development of Shaanxi's cultural undertakings. In recent years, although Shaanxi's investment in cultural construction has increased year by year, the overall proportion is still low. Although Shaanxi's cultural industry exists as an industry, it has not formed a clear guiding principle for industrial planning and industrial development, and has not established a key development and support orientation based on its own advantages. This kind of development that has no planing can only make the strong stronger and the weak weaker. In terms of industrial development, social forces still have no access standards in many aspects, which makes it difficult for social forces to formally and orderly intervene in the development of cultural industries, further exacerbating the imbalance of industrial forms. Shaanxi has rich cultural content and diverse forms, but few truly well-known cultural and arts brokerage companies and agencies. It is far from enough and unreasonable that only rely on government investment to make Shaanxi's cultural industry truly develop healthily and orderly.

Cultural Industry Management Capacity Needs to Be Improved. There are still many places that need to improve in the management and operation mechanism of the cultural industry. The first is that the awareness of service is not strong, the management is simply understood as supervision, the management departments are diverse, the primary and secondary positions are misplaced, and the responsibilities are unclear. Besides, some management departments have arbitrarily expanded the scope of management and offside enforcement. The employees of individual management departments lack relevant professional knowledge of the cultural industry and their quality is not high, which often make it difficult for the cultural industry practitioners to cope with it and severely inhibits the vitality of the cultural industry market to a certain extent. 
Inadequate Talent Team. In recent years, Shaanxi's cultural industry has entered a new period of development, but its matching talent construction and introduction mechanisms are relatively backward. Shaanxi is a major province of education. Xi'an, as a relatively concentrated city with colleges and universities in China, has a limited ability to contribute to the development of Shaanxi's cultural industry. First of all, it lacks the long-term mechanism for the introduction of talents, which has led to the fact that foreign high-quality talents in the cultural industry have not entered and laid the channels for the development of cultural industries in Shaanxi. On the other hand, the related links between the development of colleges and cultural industries are not well connected. They still follow the previous plans and goals in terms of personnel training and have not become participants and powerful promoters of Shaanxi's cultural industry development.

\section{Research on Shaanxi Culture Outbound Strategy}

Under the background of the Belt and Road Initiative, Shaanxi culture must truly implement the strategy of going abroad. The author believes that efforts should be made from the following aspects.

Emancipate the Mind and Innovation. Emancipating the mind and innovation is easy to say, but it is difficult to do. From where and how to emancipate the mind is a matter that requires careful consideration. In order for Shaanxi culture to achieve great and even leapfrog development, the first thing to be solved is the issue of ideological concepts. We must gradually develop the awareness and responsibility of developing cultural industries through the change of ideas. Second, we must get rid of the idea of opposing cultural industries with economic development. There are many people who believe that traditional culture is vulnerable to economic development. This concept is very wrong and has a strong one-sidedness. It completely contradicts the relationship between economic development and traditional culture. Finally, we must establish the overall concept of the development of the cultural industry. This overall perspective refers to the participation of the whole society in the promotion of traditional culture and the ability to use the power of the entire society to carry out the construction of the cultural industry. Culture should be tolerant, and the development of cultural industries should be even more so.

Vigorously Create An Atmosphere of Cultural Exchange. Culture should develop in communication. Different cultures have their own historical and cultural reasons for their birth and development. There is not only opposition between different cultures, but more interactions. Therefore, we should strive to create channels for communication between different cultures. In today's world, the development of any country is inseparable from each other's development. Through the creation of a rich cultural exchange atmosphere, the public will be able to perceive the charm of different cultures in communication. Vigorously creating a cultural exchange atmosphere is an urgent need for Shaanxi culture to enhance its influence, publicize Shaanxi's humanities, spiritual outlook, and development and reform achievements. At the same time, it is an urgent need to display political, economic and cultural soft power in Shaanxi, and it is an urgent need for the prosperity of Shaanxi's cultural undertakings.

Actively Guide Social Forces to Intervene. In the context of the Belt and Road Initiative, the implementation of Shaanxi's cultural outbound strategy cannot be separated from the wide participation of social forces. We must actively guide and rationalize the role of social forces in the strategy of going abroad in Shaanxi culture. Regardless of whether it is capital investment or talent participation, we must boldly rely on, organize social forces in an orderly manner and scientifically guide social forces so that social forces can become an important power in Shaanxi's cultural outbound strategy. This includes the participation of enterprises, universities, experts and scholars in related fields. We must improve the multi-level capital market system and improve financial capital and social capital to support the supporting policies for the development of cultural industries. We must use the innovation power of private capital and financial capital as the core to guide private capital and financial capital to explore and innovate in the cultural industry, and to ensure that private capital and financial capital are equal, fair and free to participate in cultural industry investment and financing through institutional design. To further promote the participation of 
cultural enterprises in capital market operations, mature large-scale cultural enterprises should support their listing financing or refinancing through the main stock market of Shanghai and Shenzhen Stock Exchanges, and continuously enhance the vitality of corporate innovation.

Standardized Management. As an industry, the cultural industry ultimately depends on market demand and its own vitality to survive and develop in the market cycle. A healthy and effective management system and market mechanism are the basis for the cultural industry to survive and develop. Good benefits cannot be separated from scientific management mechanisms and modern management methods. To change the government's leading role in the development of the cultural industry in Shaanxi province, it is necessary to deepen the reform of the cultural system and establish a scientific, efficient and coordinated cultural management system and operating mechanism that suits the characteristics of the market and cultural industries. First, we must put the reform of the cultural system and the economic system in the same important position, further deepen the reform of the cultural system and accelerate the transformation of the development mode of the cultural industry. The second is to further promote the cultural industry to face the market, expand the main body of the cultural market and establish a unified, open, competitive and orderly modern cultural market system. The third is to further transform government functions, establish a scientific and effective administrative management system and gradually explore and establish a set of cultural management systems that rely on laws, administration, markets, industry associations and meet the requirements of the socialist market economic system. Fourth, we must vigorously develop cultural public welfare undertakings, formulate tax-free policies and encourage and attract social capital to invest in cultural undertakings.

Focus on Brand Awareness. The lack of strong brand awareness is not only a problem faced by the Shaanxi culture going out, but also a common problem in the development of the national cultural industry. The analysis data of the Information Network Center of the Ministry of Culture once pointed out that the output of Chinese cultural industry has gone through three stages, such as from no audience to have audience, no market to have market. Finally there is a market, but has no brand. Many cultural types enjoy a high reputation internationally, but there are few well-known companies in the relevant cultural industries. This point is particularly prominent in Shaanxi's cultural industry. In the strategy of going global for Shaanxi's cultural industries, we must have sufficient brand awareness and build our own brand with world-class influence on the basis of mutual benefit and win-win results. Only in this way can the Shaanxi cultural industry take its own initiative in the international cultural field.

\section{Teaching Reflection}

Under the background of the Belt and Road, Shaanxi universities and colleges should fully shoulder their functions in serving local economic and social development. Both in terms of personnel training and social functions, they should focus on the issue. In education and teaching, teachers must let students understand the rich connotations of Shaanxi culture and allow students to understand in learning. The majority of Shaanxi educators must take the dissemination of Shaanxi culture as their own responsibility and do a good job in related education and teaching with a sense of responsibility and mission.

\section{Acknowledgement}

Fund Project: Strategies on Promoting Shaanxi Cultural External Communication under Background of the Belt and Road

Project Number: $2017 Z 064$

\section{Reference}

[1] A. B. Shi and Y. Sheng. The Path of Innovation in China's Foreign Communication under the Background of the Belt and Road [J]. News and Writing. 2017. 8. 
[2] D. Lu. Research on the Communication Strategy of Hui Culture under the Background of the Belt and Road [J]. Journal of Inner Mongolia University of Finance and Economics. 2018. 1.

[3] L. N. Li. The International Spread of Chinese Values under the Background of the Belt and Road [J]. Ideological and Theoretical Education. 2017. 6.

[4] T. J. Yang. The Construction of the Chinese Cultural Communication System under the Background of the Belt and Road [J]. People's Forum. 2017. 22.

[5] X. M. Zhang and others. China Culture Industry Development Report (2014) [M]. Social Sciences Academic Press. 2014. 28.

[6] L. L. Zhang and H. Wang. An Analysis of the Re-dissemination of Chinese Culture under the Background of the Belt and Road [J]. Reform and Opening Up, 2017.18.

[7] L. Ding. Study on the Spread of Shaanxi Culture in the Silk Road Economic Belt [J]. Today Media, 2015. 8.

[8] Y. Chen. Some Considerations on the Development of Cultural Industry in Shaanxi Province. Science and Technology Information Development and Economy. 2012: 156-158. 